\title{
Heck Reactions with Ultralow Concentration of Transition Metals under Microwave Irradiation
}

\author{
Hongjun Wang ${ }^{1,2}$, Haiyang Cheng ${ }^{1,2^{*}}$, Fengyu Zhao ${ }^{1,2^{*}}$ \\ ${ }^{1}$ State Key Laboratory of Electroanalytical Chemistry, Changchun Institute of Applied Chemistry, \\ Chinese Academy of Sciences, Changchun, China \\ ${ }^{2}$ Laboratory of Green Chemistry and Process, Changchun Institute of Applied Chemistry, \\ Chinese Academy of Sciences, Changchun, China \\ Email: "hycyl@ciac.ac.cn, ${ }^{*}$ zhaofy@ciac.ac.cn
}

Received December 5, 2013; revised January 15, 2014; accepted January 22, 2014

Copyright (c) 2014 Hongjun Wang et al. This is an open access article distributed under the Creative Commons Attribution License, which permits unrestricted use, distribution, and reproduction in any medium, provided the original work is properly cited. In accordance of the Creative Commons Attribution License all Copyrights (C) 2014 are reserved for SCIRP and the owner of the intellectual property Hongjun Wang et al. All Copyright (C) 2014 are guarded by law and by SCIRP as a guardian.

\section{ABSTRACT}

The Heck coupling reactions of aryl halides and olefins were performed under the microwave assistance. Interestingly, the ultralow concentration of transition metals (in ppb) coming from the reactants could catalyze the Heck coupling reactions under microwave irradiation, without addition of any catalysts, ligands and phasetransfer agents. The influences of bases, solvents and temperature were discussed, and the reaction rate was enhanced largely in the mixed solvents of NMP and water due to the solubility of base in water.

\section{KEYWORDS}

\section{Heck Reaction; Microwave Irradiation; Ultralow Concentration; Transition Metal Catalysts; Water}

\section{Introduction}

Heck reaction of aryl halide and olefin is still attracting much attention, for it is one of the important methods to build up new carbon-carbon bond [1]. Heck reactions are most frequently performed in polar solvents such as acetonitrile, dimethyl sulphoxide, or dimethylacetamide and $\mathrm{N}$-methylpyrrolidone (NMP) in the presence of palladium catalysts. It was reported that the addition of water could markedly accelerate the Heck reactions in the presence of $\mathrm{Pd}(\mathrm{OAc})_{2}$ or $\mathrm{Pd} / \mathrm{C}$ catalysts, but colloidal palladium particles were formed in these cases [2-5]. Reetz et al. [3] and de Vries et al. [4] had reported that the Heck reactions could be run in the mixed solvent of $\mathrm{NMP}$ and water in the presence of quantities of $\mathrm{Pd}(\mathrm{OAc})_{2}$, and they suggested that the reaction be proceeded via the formation of palladium colloids. Recently, the real active species has been well discussed for the Heck reactions catalyzed with heterogeneous catalyst of supported palladium since the Heck reactions were reported to be catalyzed homogeneously by the dissolved palladium in the solution [6,7]. It was reported that the ligand-free

${ }^{*}$ Corresponding authors. palladium catalyst of $\mathrm{Pd}(\mathrm{OAc})_{2}$ could be recycled successfully by adding the supports like active carbon or silica into the reaction solution [8]. Water is the most abundant, cheap, safe, and environmentally benign solvent in nature and the study of organic reaction in/on water is an important theme of current research from the point of green chemistry [9]. The Heck coupling of iodobenzene with styrene could be performed in supercritical water in the absence of any transition metal catalysts [10]. Microwave heating has been shown to dramatically reduce reaction times, increase product yields, and enhance product purities compared to conventional synthetic methods in organic synthesis [9], and Suzuki and Heck reactions were reported to proceed successfully under microwave irradiation with or without the addition of catalyst [11-29]. Leadbeater and coworkers reported that Suzuki coupling reactions could carry out in water in the presence of tetrabutylammonium bromide (TBAB) as a phase-transfer agent by microwave irradiation in the absence of transition metal catalysts [14,15], while subsequently they found that the transition metals contaminated to a level of 50 and $500 \mathrm{ppb}$ (contained in bases) should be possible for Suzuki and Heck coupling reactions 
respectively rather than their previous suggested nontransition metal-mediated pathway $[16,17]$. However, the presence of phase-transfer agent makes it difficult to separate the product and the solvent.

In the present work, microwave irradiation can promote the Heck coupling reactions of aryl halides and olefins in the presence of ultralow transition metals in various solvents and in the absence of ligands and phase-transfer agents, and a high conversion and selectivity were obtained. The influences of several parameters such as solvent, base and reaction temperature have been discussed, and the existence of transition metals in the reaction solution as well as the reactions in the presence of ultralow concentration of palladium compound has been examined.

\section{Results and Discussion}

The coupling reactions of styrene and aryl halides of iodobenzene, bromobenzene and chlorobenzene could be promoted by microwave irradiation in the presence of ultralow transition metals, in which several products have been detected except for the main coupling product of stilbene (1) as shown in the Scheme 1.

\subsection{The Heck Reaction in the Presence of Utralow of $\mathrm{Pd}(\mathrm{OAc})_{2}$}

The Heck reactions of iodobenzene with styrene have been performed in the presence of $\mathrm{Pd}(\mathrm{OAc})_{2}$ with low $\mathrm{Pd}$ concentrations of 0.5 - 2 ppm without using any ligands and phase transfer reagents in water, and the results are shown in Table 1, Under the microwave irradiation at $200^{\circ} \mathrm{C}$, when the reaction was carried out in the presence of $0.5 \mathrm{ppm} \mathrm{Pd}$ in $\mathrm{H}_{2} \mathrm{O}$, the conversion of iodobenzene achieved $26 \%$ and the selectivity to stilbene reached $85 \%$, while the conversion and selectivity were increased to $62 \%$ and $97 \%$ respectively when the Pd concentration was enhanced to 2 ppm (Table 1, Entries 1 and 2). In the mixed solvent of THF and water, the conversion increased also with the concentration of $\mathrm{Pd}$, and the selectivity decreased slightly (Table 1, Entries 3 and 4), but the selectivity was still higher than the results obtained in the mixed solvents of NMP and water, in which even though the higher conversion could be obtained (Table 1, Entries 4 and 5). When enhanced the temperature to $245^{\circ} \mathrm{C}$, the conversion of iodobenzene achieved $100 \%$ at reaction for $30 \mathrm{~min}$, and the yield to stilbene reached $73 \%$ (Table 1, Entry 6). However, when the blank reaction was carried out without addition of $\mathrm{Pd}(\mathrm{OAC})_{2}$, surprisingly, a very high conversion of $88 \%$ was obtained and the selectivity to stilbene reached $60 \%$ (Table 1, Entry 7). We have repeated the reaction several times to check the reproducibility of the reaction data, including with new reaction tube to decrease the possible influences, but the

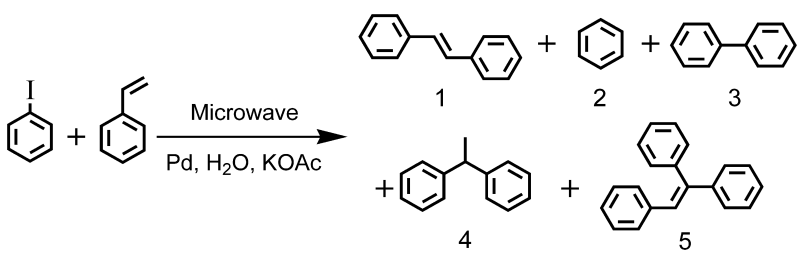

Scheme 1 . Heck reaction of iodobenzene with styrene under the microwave irradiation.

similar results have been obtained. It was been reported that the Heck reaction could occur in supercritical water in the absence of catalysts [10], For the present work, the reactions were carried out in a closed vessel, thus reactions were carried out under a pressure higher than the atmosphere, but the system was far from the conditions of supercritical water for that the pressure in the reaction system was lower than $2 \mathrm{MPa}$. The coupling reactions could be promoted by microwave irradiation in the transition metal-free conditions $[14,15]$, while subsequently it was found that the ultralow transition metal concentrations should be possible for catalyzing the reactions $[16,17]$. For confirming the present reaction is real transition metal-free or not, the ICP-MS was used to examine transition metals like $\mathrm{Pd}, \mathrm{Ru}, \mathrm{Pt}$ and $\mathrm{Rh}$ in the reaction solution, all these metals are active for the Heck coupling reactions. These transition metals were detected in the reaction solution in a concentration of $3.418 \mathrm{ppb} \mathrm{Pd}$, $1.162 \mathrm{ppb} \mathrm{Rh}, 1.048 \mathrm{ppb} \mathrm{Ru}$ and $0.750 \mathrm{ppb} \mathrm{Pt}$, and the transition metals mainly come from the mixture of reactants rather than base like KOAc in the present work. Although the concentration of the transition metals is quite lower than that reported in literature (500 ppb) [17], such low concentration of transition metal is still effective for the Heck reaction under microwave irradiation. Then, the influence of several reaction parameters were examined and discussed on the Heck reactions without addition of any ligands, phase transfer reagents and metal catalysts.

\subsection{The Influence of Solvent and Temperature}

Table 2 shows the reaction of iodobenzene with styrene in several solvent systems at different temperatures. Under the reaction conditions used, the solvent presents a significant effect on the conversion and selectivity in the presence of a base of KOAc. Comparing all the solvents used, DMF and NMP are more effective (Table 2, Entries 1 and 2), but water and THF are less effective (Table 2, Entries 3 and 4). When ethanol was used, no product could be detected at $180^{\circ} \mathrm{C}$ (Table 2, Entry 5). It is obviously that the total conversion and product yield could be improved largely by adding a co-solvent of water to mix with the organic solvents even at low reaction temperature (Table 2, Entries 6 and 7). It was considered that the presence of water could increase the solubility of 
Table 1. Results for Heck coupling reactions in the presence of $\operatorname{Pd}(\mathrm{OAc})_{2}$.

\begin{tabular}{|c|c|c|c|c|c|c|c|}
\hline Entry & $\mathrm{Pd}^{2+}(\mathrm{ppm})$ & $\begin{array}{l}\text { Catalyst loading } \\
\text { (mol \%) }\end{array}$ & Solvent & $\mathrm{T}\left({ }^{\circ} \mathrm{C}\right)$ & Conversion (\%) & $\begin{array}{c}\text { Selectivity to } \\
\text { stilbene (\%) }\end{array}$ & $\begin{array}{c}\text { Yield to } \\
\text { stilbene (\%) }\end{array}$ \\
\hline 1 & 0.5 & $0.67 \times 10^{-3}$ & $\mathrm{H}_{2} \mathrm{O}$ & 200 & 26 & 85 & 22 \\
\hline 2 & 2 & $2.67 \times 10^{-3}$ & $\mathrm{H}_{2} \mathrm{O}$ & 200 & 62 & 97 & 60 \\
\hline 3 & 0.5 & $0.67 \times 10^{-3}$ & $\mathrm{THF}+\mathrm{H}_{2} \mathrm{O}$ & 180 & 6 & 94 & 6 \\
\hline 4 & 2 & $2.67 \times 10^{-3}$ & $\mathrm{THF}+\mathrm{H}_{2} \mathrm{O}$ & 180 & 23 & 89 & 20 \\
\hline 5 & 2 & $2.67 \times 10^{-3}$ & $\mathrm{NMP}+\mathrm{H}_{2} \mathrm{O}$ & 180 & 64 & 67 & 43 \\
\hline 6 & 2 & $2.67 \times 10^{-3}$ & $\mathrm{NMP}+\mathrm{H}_{2} \mathrm{O}$ & 245 & 100 & 73 & 73 \\
\hline 7 & - & - & $\mathrm{NMP}+\mathrm{H}_{2} \mathrm{O}$ & 245 & 88 & 60 & 53 \\
\hline
\end{tabular}

Reaction conditions: 5 mmol iodobenzene, 5 mmol styrene, 5 mmol KOAc, 6 ml solvent, in mixed solvent $\mathrm{H}_{2} \mathrm{O} /$ organic solvent: 1/5, 30 min.

Table 2. Influence of solvent and temperature on the reactions of iodobenzene with styrene.

\begin{tabular}{|c|c|c|c|c|c|c|}
\hline Entry & Solvent & $\begin{array}{c}\text { Temperature } \\
\left({ }^{\circ} \mathrm{C}\right)\end{array}$ & Conversion (\%) & $\begin{array}{l}\text { Selectivity of } \\
\text { stilbene (\%) }\end{array}$ & $\begin{array}{c}\text { Yield of } \\
\text { stilbene (\%) }\end{array}$ & $\mathrm{E}: \mathrm{Z}$ \\
\hline 1 & DMF & 245 & 37 & 46 & 17 & $90: 10$ \\
\hline 2 & NMP & 210 & 33 & 55 & 18 & $85: 15$ \\
\hline 3 & $\mathrm{H}_{2} \mathrm{O}$ & 210 & 5 & 58 & 3 & 100 \\
\hline 4 & THF & 210 & 14 & 7 & 1 & 100 \\
\hline 5 & Ethanol & 180 & $\mathrm{Nd}$ & - & - & - \\
\hline $6^{\mathrm{b}}$ & $\mathrm{DMF}+\mathrm{H}_{2} \mathrm{O}$ & 210 & 42 & 82 & 34 & $80: 20$ \\
\hline $7^{\mathrm{b}}$ & $\mathrm{NMP}+\mathrm{H}_{2} \mathrm{O}$ & 180 & 44 & 10 & 4 & 100 \\
\hline $8^{\mathrm{b}}$ & $\mathrm{NMP}+\mathrm{H}_{2} \mathrm{O}$ & 245 & 88 & 60 & 53 & $65: 35$ \\
\hline $9^{b, c}$ & $\mathrm{NMP}+\mathrm{H}_{2} \mathrm{O}$ & 245 & 76 & 66 & 50 & $77: 23$ \\
\hline
\end{tabular}

Reaction conditions: $5 \mathrm{mmol}$ iodobenzene, $5 \mathrm{mmol}$ styrene, $5 \mathrm{mmol} \mathrm{KOAc,} 6 \mathrm{ml}$ solvent, $30 \mathrm{~min}$. ${ }^{\mathrm{a}}$ Yield of stilbene was calculated based on the total conver-

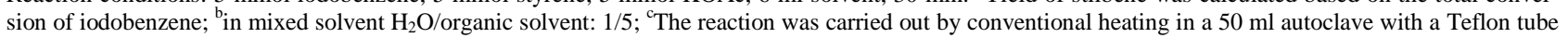
for 8 h. Nd: not detected.

inorganic bases in the solution and then enhance the reaction conversion. High total conversion (88\%) of iodobenzene and yield (53\%) of coupling product, stilbene, have been obtained in the mixed solvents of NMP and water (Table 2, Entry 7). In the present work, the Heck coupling product contains two isomers of transand cis-stilbene, and the ratio of trans- to cis- (E:Z) decreases with the total conversion. Which is contrast to the results reported for the Heck reactions in the supercritical water [10]. Furthermore, the reaction temperature presented a significant effect on the total conversion and product yield, the higher conversion and yield were obtained at the higher reaction temperature (Table 2, Entries 7 and 8). Moreover, when the reaction was carried out with the conventional heating method in an autoclave fitted with a teflon cell, the Heck coupling product could also be produced, but the total conversion of reaction for $8 \mathrm{~h}$ is lower than that obtained under the microwave irradiation for a short time of $0.5 \mathrm{~h}$ (Table 2, Entries 8 and 9).

\subsection{The Influence of Base}

The presence of base is necessary to bind the hydrogen halide formed during the catalytic Heck coupling reactions [1], the effect of base in the present work has also been investigated. Experiments were carried out in the presence of $\mathrm{Na}_{3} \mathrm{PO}_{4}, \mathrm{Na}_{2} \mathrm{CO}_{3}, \mathrm{~K}_{2} \mathrm{CO}_{3}, \mathrm{Cs}_{2} \mathrm{CO}_{3}, \mathrm{Et}_{3} \mathrm{~N}$, $\mathrm{NaOAc}$ and KOAc, when $\mathrm{Na}_{3} \mathrm{PO}_{4}$ and $\mathrm{Na}_{2} \mathrm{CO}_{3}$ were used, product could not be detected. While, the other bases are effective under the reaction conditions used as shown in Table 3. The bases exhibited a strong influence on both the total conversion and product yield, and KOAc is the most effective for forming coupling product of stilbene (Table 3, Entry 2), it shows that higher ratio of E: Z could be obtained with acetates compared to that of carbonates (Table 3, Entries 1, 3, 4 and 5). In our present work, the Heck reaction could occur with all the bases and it is irrespective to the base used like $\mathrm{Na}_{2} \mathrm{CO}_{3}, \mathrm{Et}_{3} \mathrm{~N}, \mathrm{~K}_{2} \mathrm{CO}_{3}$ and $\mathrm{KOAc}$, but depended significantly on the temperature and solvents used.

\subsection{The Heck Reactions with Different Substrates}

It is well known that the C-C coupling reactions with chlorobenzene and bromobenzene are quite difficult even in the presence of the active catalysts. Choudary et al. have obtained high turnover numbers in Heck couplings with aryl chlorides by using supported nano Pd catalysts. They suggested that the reaction proceeded on the surface of the nanoparticles [30]. In the present work, the 
Heck coupling reactions of chlorobenzene and bromobenzene with styrene have been also checked without addition of catalysts, the results are shown in Table 4 . It indicated that a certain conversion could be obtained for coupling reactions of chlorobenzene and bromobenzene with styrene under microwave irradiation. However, several by-products such as benzene and biaryl were formed. For the reaction of bromobenzene with styrene, a $28 \%$ yield of coupling product was obtained (Table 4 , Entry 2), while the yield was less than $2 \%$ for the reaction of chlorobenzene and styrene (Table 4, Entry 1). In the literature, $\mathrm{PdCl}_{2}$ catalyzed Heck reactions in ionic liquids was reported to be an effective system for reactions of iodobenzene or bromobenzene with styrene, but only $10 \%$ yield of stilbene was obtained from chlorobenzene and styrene in the presence of $0.16 \mathrm{~mol} \% \mathrm{PdCl}_{2}$ [31]. When methyl acrylate and butyl acrylate were used as olefin to couple with iodobenzene, lower conversions and selectivities have been obtained compared with that of styrene (Table 4, Entries 3 - 5).

\section{Conclusion}

Under microwave irradiation, without addition of any catalysts, ligands and phase-transfer agents, Heck coupling reactions of aryl halides and styrene could be smoothly performed in the presence of ultralow transition metals come from the reactants. The microwave irradiation is an effective method for Heck coupling reactions compared with conventional heating method. Moreover, the chlorobenzene and bromobenzene have also showed reactivity under the microwave irradiation with the ultralow concentration of transition metals, therefore the present reaction system is an effective one for the Heck coupling reactions.

\section{Experimental Section}

The reactants of chlorobenzene (99.5 wt.\%), methylacrylate (99.5 wt.\%), buthylacrylate (98 wt.\%) were purchased from Tianjin Chemical Reagent Co. Ltd., and iodobenzene (97 wt.\%), bromobenzene (99.5 wt.\%), styrene (99.0 wt.\%) were purchased from Shanghai Chemical Reagent Co. Ltd. and used as they were received without further purification. Potassium acetate (KOAc, 99 wt.\%, Guangdong Xilong Chemical Co. Ltd.) was used as it was received, the bases of triethylamine $\left(\mathrm{Et}_{3} \mathrm{~N}\right)$, sodium carbonate $\left(\mathrm{Na}_{2} \mathrm{CO}_{3}\right)$, potassium carbonate $\left(\mathrm{K}_{2} \mathrm{CO}_{3}\right)$, Cesium carbonate $\left(\mathrm{Cs}_{2} \mathrm{CO}_{3}\right)$, sodium acetate $\left(\mathrm{NaOAc} \cdot 3 \mathrm{H}_{2} \mathrm{O}\right)$, sodium phosphate $\left(\mathrm{Na}_{3} \mathrm{PO}_{4}\right)$ and solvents of $\mathrm{N}$-methylpyrrolidone (NMP), Dimethyl formamide (DMF), tetrahydrofuran (THF), Ethanol from Beijing Chemical Co. Ltd. are of analytical grade and used also without further purification. The deionized water was used for all the experiments. The reactions were carried out using a microwave irradiation reactor system (Initiator, Biotage, Sweden). The representative example of a Heck coupling reaction of iodobenzene with styrene was carried out as follows: The reactants of iodobenzene, styrene and base $5 \mathrm{mmol}$ each were added into the $10 \mathrm{ml}$ glass tube reactor, then introduce $6 \mathrm{ml}$ solvent and put a magnetic stirrer bar into the reactor, after the vessel was sealed with a septum, it was placed into the microwave cavity. When the reaction system reached the desired temperature, the reaction was started with continual stirring by a magnetic stirrer (900 rpm) during the reaction. The microwave cavity opened automatically when the reactor was cooled to room temperature. The reaction mixture was extracted by using dichloromethane, then analyzed with gas chromatography (GC-Shimadza-14C, FID, Capillary column, Rtx-Wax $30 \mathrm{~m} \times 0.53 \mathrm{~mm} \times 0.25 \mu \mathrm{m}$ ) and identified by

Table 3. Influence of base on the reaction of iodobenzene and styrene.

\begin{tabular}{cccccc}
\hline Entry & Base & Conversion (\%) & Selectivity to stilbene (\%) & Yield to stilbene (\%) & E:Z \\
\hline 1 & $\mathrm{~K}_{2} \mathrm{CO}_{3}$ & 26 & 67 & 17 & $49: 51$ \\
2 & $\mathrm{Et}_{3} \mathrm{~N}$ & 44 & 69 & 30 & $74: 26$ \\
3 & $\mathrm{Cs}_{2} \mathrm{CO}_{3}$ & 49 & 32 & 16 & $37: 63$ \\
4 & ${\mathrm{NaOAc} \cdot 3 \mathrm{H}_{2} \mathrm{O}}_{5}$ & 57 & 63 & 36 & $87: 13$ \\
5 & $\mathrm{KOAc}$ & 88 & 60 & 53 & $65: 35$ \\
\hline
\end{tabular}

Reaction conditions: $5 \mathrm{mmol}$ iodobenzene, $5 \mathrm{mmol}$ styrene, $5 \mathrm{mmol}$ base, $5 \mathrm{ml} \mathrm{NMP}, 1 \mathrm{ml} \mathrm{H} \mathrm{H}_{2}$, $245^{\circ} \mathrm{C}, 30 \mathrm{~min}$. ${ }^{\mathrm{a}}$ Yield of stilbene was calculated based on the total conversion of iodobenzene.

Table 4. Results for Heck coupling reactions promoted by microwave irradiation at $245^{\circ} \mathrm{C}$.

\begin{tabular}{cccccc}
\hline Entry & Aryl halides & Olefine & Conversion (\%) & Selectivity to coupling product (\%) & Yield to coupling product (\%) \\
\hline 1 & Chlorobenzene & Styrene & 27 & 9 & 2 \\
2 & Bromobenzene & Styrene & 88 & 32 & 28 \\
3 & Iodobenzene & Styrene & 88 & 60 & 53 \\
4 & Iodobenzene & Methylacrylate & 18 & 52 & 9 \\
5 & Iodobenzene & Buthylacrylate & 27 & 49 & 13 \\
\hline
\end{tabular}

Reaction conditions: 5 mmol aryl halide, 5 mmol olefin, 5 mmol KOAc, 5 ml NMP, 1 ml $\mathrm{H}_{2} \mathrm{O}, 30$ min. 
gas chromatography/mass spectrometry (GC/MS, Agilent 5890). The product yield was calculated based on the total conversion of iodobenzene. Inductively coupled plasma mass spectrometry (ICP-MS, TJA, POEMS) was used to examine the transition metals in reaction solution.

\section{Acknowledgements}

The authors gratefully acknowledge financial support from the One Hundred Talent Program of CAS.

\section{REFERENCES}

[1] R. F. Heck, "Palladium-Catalyzed Vinylation of Organic Halides,” In: Organic Reactions, Vol. 27, Wiley, New York, 1982, pp. 345-390. http://dx.doi.org./10.1002/0471264180.or027.02

[2] F. Y. Zhao, M. Shirai and M. Arai, "Palladium-Catalyzed Homogeneous and Heterogeneous Heck Reactions in NMP and Water-Mixed Solvents Using Organic, Inorganic and Mixed Bases,” Journal of Molecular Catalysis A: Chemical, Vol. 154, No. 1-2, 2000, pp. 39-44. http://dx.doi.org/10.1016/S1381-1169(99)00369-6

[3] M. T. Reetz, E. Westermann, R. Lohmer and G. Lohmer, "A Highly Active Phosphine-Free Catalyst System for Heck Reactions of Aryl Bromides,” Tetrahedron Letters, Vol. 39, No. 46, 1998, pp. 8449-8452. http://dx.doi.org/10.1016/S0040-4039(98)01967-4

[4] A. H. M. de Vries, J. Mulders, J. H. M. Mommers, H. J. W. Henderickx and J. G. de Vries, "Homeopathic Ligand-Free Palladium as a Catalyst in the Heck Reaction. A Comparison with a Palladacycle," Organic Letters, Vol. 5, No. 18, 2003, pp. 3285-3288. http://dx.doi.org/10.1021/ol035184b

[5] L. M. Tao, Q. G. Li, W. Q. Liu, Y. Zhou and J. F. Zhou, "Water-Promoted Palladium-Catalysed Heck CrossCoupling Reactions of Aryl Halides with Alkenes in TBAB," Journal of Chemical Research, Vol. 35, No. 3, 2011, pp. 154-156. http://dx.doi.org/10.3184/174751911X12979690024078

[6] F. Y. Zhao, B. M. Bhanage, M. Shirai and M. Arai, "Heck Reactions of Iodobenzene and Methyl Acrylate with Conventional Supported Palladium Catalysts in the Presence of Organic and/or Inorganic Bases without Ligands," Chemistry A European Journal, Vol. 6, No. 5, 2000, pp. 843-848.

http://dx.doi.org/10.1002/(SICI)1521-3765(20000303)6:5 $<843::$ AID-CHEM843>3.0.CO;2-G

[7] F. Y. Zhao, M. Shirai, Y. Ikushima and M. Arai, "The Leaching and Re-Deposition of Metal Species from and onto Conventional Supported Palladium Catalysts in the Heck Reaction of Iodobenzene and Methyl Acrylate in N-Methylpyrrolidone," Journal of Molecular Catalysis A: Chemical, Vol. 180, No. 1-2, 2002, pp. 211-219.

http://dx.doi.org/10.1016/S1381-1169(01)00436-8

[8] F. Y. Zhao, K. Murakami, M. Shirai and M. Arai, "Recyclable Homogeneous/Heterogeneous Catalytic Systems for Heck Reaction through Reversible Transfer of Palladium Species between Solvent and Support," Journal of
Catalysis, Vol. 194, No. 2, 2000, pp. 479-483. http://dx.doi.org/10.1006/jcat.2000.2934

[9] D. Dallinger and C. O. Kappe, "Microwave-Assisted Synthesis in Water as Solvent," Chemical Reviews, Vol. 107, No. 6, 2007, pp. 2563-2591. http://dx.doi.org/10.1021/cr0509410

[10] R. Zhang, O. Sato, F. Y. Zhao, M. Sato and Y. Ikushima, "Heck Coupling Reaction of Iodobenzene and Styrene Using Supercritical Water in the Absence of a Catalyst," Chemistry: A European Journal, Vol. 10, No. 6, 2004, pp. 1501-1506. http://dx.doi.org/10.1002/chem.200305542

[11] X. G. Xie, J. P. Lu, B. Chen, J. J. Han, X. G. She and X. F. Pan, "Pd/C-Catalyzed Heck Reaction in Ionic Liquid Accelerated by Microwave Heating," Tetrahedron Letters, Vol. 45, No. 4, 2004, pp. 809-811.

http://dx.doi.org/10.1016/j.tetlet.2003.11.042

[12] D. E. Bergbreiter and S. Furyk, "Microwave Promoted Heck Reactions Using an Oligo (Ethylene Glycol)-Bound SCS Palladacycle under Thermomorphic Conditions," Green Chemistry, Vol. 6, No. 6, 2004, pp. 280-285. http://dx.doi.org/10.1039/b316342c

[13] D. Villemin and F. Caillot, "Microwave Mediated Palladium-Catalysed Reactions on Potassium Fluoride/Alumina without Use of Solvent," Tetrahedron Letters, Vol. 42, No. 4, 2001, pp. 639-642. http://dx.doi.org/10.1016/S0040-4039(00)02027-X

[14] N. E. Leadbeater and M. Marco, "Transition-Metal-Free Suzuki-Type Coupling Reactions,” Angewandte Chemie International Edition, Vol. 42, No. 12, 2003, pp. 14071409. http://dx.doi.org/10.1002/anie.200390362

[15] N. E. Leadbeater and M. Marco, “Transition-Metal-Free Suzuki-Type Coupling Reactions: Scope and Limitations of the Methodology,” Journal of Organic Chemistry, Vol. 68, No. 14, 2003, pp. 5660-5667. http://dx.doi.org/10.1021/jo034230i

[16] R. K. Arvela, N. E. Leadbeater, M. S. Sangi, V. A. Williams, P. Granados and R. D. Singer, "A Reassessment of the Transition-Metal Free Suzuki-Type Coupling Methodology," Journal of Organic Chemistry, Vol. 70, No. 1, 2005, pp. 161-168. http://dx.doi.org/10.1021/jo048531j

[17] R. K. Arvela and N. E. Leadbeater, "Microwave-Promoted Heck Coupling Using Ultralow Metal Catalyst Concentrations," Journal of Organic Chemistry, Vol. 70, No. 5, 2005, pp. 1786-1790. http://dx.doi.org/10.1021/jo048052k

[18] N. E. Leadbeater, "Fast, Easy, Clean Chemistry by Using Water as a Solvent and Microwave Heating: The Suzuki Coupling as an Illustration," Chemical Communications, No. 23, 2005, pp. 2881-2902. http://dx.doi.org/10.1039/b500952a

[19] J. Yan, M. Zhu and Z. S. Zhou, "Rapid Microwave-Promoted Catalyst- and Base-Free Suzuki-Type Coupling Reaction in Water," European Journal of Organic Chemistry, Vol. 2006, No. 9, 2006, pp. 2060-2062. http://dx.doi.org/10.1002/ejoc.200500915

[20] S. S. Yi, D. H. Lee, E. Sin and Y. S. Lee, "ChitosanSupported Palladium(0) Catalyst for Microwave-Prompted Suzuki Cross-Coupling Reaction in Water," Tetrahedron Letters, Vol. 48, No. 38, 2007, pp. 6771-6775. 
http://dx.doi.org/10.1016/j.tetlet.2007.07.093

[21] C. Schmoeger, T. Szuppa, A. Tied, F. Schneider, A. Stolle and B. Ondruschka, "Pd on Porous Glass: A Versatile and Easily Recyclable Catalyst for Suzuki and Heck Reactions,” Chemsuschem, Vol. 1, No. 4, 2008, pp. 339347. http://dx.doi.org/10.1002/cssc.200700159

[22] B. K. Singh, N. Kaval, S. Tomar, E. Van der Eycken and V. S. Parmar, "Transition Metal-Catalyzed Carbon-Carbon Bond Formation Suzuki, Heck, and Sonogashira Reactions Using Microwave and Microtechnology," Organic Process Research \& Development, Vol. 12, No. 3, 2008, pp. 468-474. http://dx.doi.org/10.1021/op800047f

[23] K. M. Dawood and M. M. El-Deftar, "Microwave-Assisted C-C Cross-Coupling Reactions of Aryl and Heteroaryl Halides in Water," Arkivoc, Vol. 2010, No. 9, 2010, pp. 319-330. http://dx.doi.org/10.3998/ark.5550190.0011.930

[24] B. K. Allam and K. N. Singh, “An Efficient PhosphineFree Heck Reaction in Water Using Pd(L-Proline)(2) as the Catalyst Under Microwave Irradiation," Synthesis, Vol. 2011, No. 7, 2011, pp. 1125-1131. http://dx.doi.org/10.1055/s-0030-1258452

[25] D. de L. Martins, H. M. Alvarez, L. C. S. Aguiar and O. A. C. Antunes, "Heck Reactions Catalyzed by Pd(0)-PVP Nanoparticles under Conventional and Microwave Heating,” Applied Catalysis A: General, Vol. 408, No. 1-2, 2011, pp. 47-53.

http://dx.doi.org/10.1016/j.apcata.2011.09.014

[26] A. K. Gupta, N. Singh and K. N. Singh, "Microwave Assisted Organic Synthesis: Cross Coupling and Multicomponent Reactions,” Current Organic Chemistry, Vol. 17, No. 5, 2013, pp. 474-490. http://dx.doi.org/10.2174/1385272811317050005

[27] A. R. Hajipour and F. Rafiee, "Microwave-Assisted Suzuki Cross-Coupling Reactions Using Dimeric OrthoPalladated Complex of Tribenzylamine," Organic Preparations and Procedures International, Vol. 45, No. 6, 2013, pp. 465-472.

http://dx.doi.org/10.1080/00304948.2013.834772

[28] K. Kranjc and M. Kocevar, "From Conventional Reaction Conditions to Microwave-Assisted Catalytic Transformations of Various Substrates. State of the Art in 2012 (Part B: Catalysis)," Current Organic Chemistry, Vol. 17, No. 5, 2013, pp. 457-473. http://dx.doi.org/10.2174/1385272811317050004

[29] Y. K. Zhang, Z. L. Lv, H. Y. Zhong, M. F. Zhang, T. Zhang, W. N. Zhang and K. Li, "Efficient Heck CrossCoupling of 3-Iodo-Benzopyrones with Olefins under Microwave Irradiation without Phosphine,” Tetrahedron, Vol. 68, No. 47, 2012, pp. 9777-9787. http://dx.doi.org/10.1016/j.tet.2012.09.017

[30] B. M. Choudary, S. Madhi, N. S. Chowdari, M. L. Kantam and B. Sreedhar, "Layered Double Hydroxide Supported Nanopalladium Catalyst for Heck-, Suzuki-, Sonogashira-, and Stille-Type Coupling Reactions of Chloroarenes," Journal of the American Chemical Society, Vol. 124, No. 47, 2002, pp. 14127-14136. http://dx.doi.org/10.1021/ja026975w

[31] S. H. Li, Y. J. Lin, H. B. Xie, S. B. Zhang and J. N. Xu, "Bronsted Guanidine Acid-Base Ionic Liquids: Novel Reaction Media for the Palladium-Catalyzed Heck Reaction," Organic Letters, Vol. 8, No. 3, 2006, pp. 391-394. http://dx.doi.org/10.1021/ol052543p. 